Meta

Journal des tradlucteurs

Translators' Journal

\title{
Translators and Machines - Can they Cooperate?
}

\section{Alan K. Melby}

Volume 26, numéro 1, mars 1981

L'informatique au service de la traduction

Machine Aids to Translation

URI : https://id.erudit.org/iderudit/003619ar

DOI : https://doi.org/10.7202/003619ar

Aller au sommaire du numéro

Éditeur(s)

Les Presses de l'Université de Montréal

ISSN

0026-0452 (imprimé)

1492-1421 (numérique)

Découvrir la revue

\section{Citer cet article}

Melby, A. K. (1981). Translators and Machines - Can they Cooperate? Meta, 26(1), 23-34. https://doi.org/10.7202/003619ar d'utilisation que vous pouvez consulter en ligne.

https://apropos.erudit.org/fr/usagers/politique-dutilisation/ 


\section{Translators and Machines - Can they Cooperate?}

Alan K. Melby

Despite early fears and thirty years of work on machine translation, very few human translators have been replaced by computers. The METEO system (Chandioux, 1976), one of the most successful machine translation efforts, still uses humans to translate problem sentences. The computer translates only the straightforward portions of daily weather forecasts, which become extremely boring work for human translators.

The time has finally come when translators and machines can call a truce and begin an era of significant cooperation. Machines can become servants rather than ennemies.

This article is divided into five sections: 1) Some fundamental questions about the nature of machine translation, 2) a brief history of machine translation, 3) a description of an experiment in cooperative translation called ITS (Interactive Translation System), 4) a prediction of the future of ITS, and 5) a few suggestions to translators who want to prepare for the future.

\section{SOME FUNDAMENTAL QUESTIONS}

There are three fundamental questions that need to be considered by anyone working in machine translation.

Question one: Is there an essential difference between humans and machines? This may not seem to be an issue to some because the answer is so obvious. The trouble is that to some there is obviously an essential difference and to some there is obviously not. The author assumes that most linguists and translators, being basically humanists, believe humans and machines to be fundamentally different and that computers cannot think and will never do so. The following two quotations from respected scientists reveal a viewpoint which does not clearly distinguish humans and machines.

George Miller, a psychologist, has written :

Many psychologists have come to take for granted in recent years... that men and computers are merely two different species of a more abstract genus called 'information processing systems'. The concepts that describe abstract information processing systems must, perforce, describe any particular examples of such systems (Miller, 1972).

Simon and Newell, researchers in Artificial Intelligence, claimed over twenty years ago :

There are now in the world machines that think, that learn and that create. Moreover, their ability to do these things is going to increase rapidly 
until - in the visible future - the range of problems they can handle will be coextensive with the range to which the human mind has been applied (Simon and Newell, 1958).

Question two: What is translation? Translation is a very broad term. It involves a source language document and a target language document which correspond in some way. But translation may be technical or literary. It may retain the source culture or yield to target culture. The territory covered by movement between extremes on several axes is so broad that one suspects that machines adapt more easily to certain areas of the terrain than others. Indeed, machines have shown themselves quite useful in some formal, technical translation, but have not even ventured into the province of creative literary translation.

Question three: Is translation an essentially human activity? One answers this question with two questions - namely questions one and two. Whether translation is essentially human depends on what kind of translation is involved and whether humans and machines are essentially different. If translation is restricted to weather forecasts then translation is not essentially human because the METEO system does quite a decent job of translating Canadian weather forecasts every day. If, on the other hand, translation is expanded to include the best of literary translation and there is any essential difference between people and machines, then translation is essentially a human activity.

Now where do all these questions lead us? The author assumes that most translators will agree in general with the following reply. Humans are essentially different from machines and any kind of translation which is challenging and creative is an aspect of human activity which will never be achieved by machines.

The history of machine translation may be easier to understand if one attempts to determine where various workers have stood relative to these fundamental questions.

\section{HISTORY OF MACHINE TRANSLATION}

In the 1950's work in machine translation was done primarily by people who were not linguists. An influential and typical attitude was that of Warren Weaver, Director of the Natural Sciences Division of the Rockefeller Foundation. In 1949, Weaver circulated a personal memorandum calling for research in machine translation. He admitted that a word-for-word translation is not adequate, but presented as obvious the claim that a translation system which considered two or three words on either side of the word in question would surely be able to produce a correct translation. He was implicitly assuming that machine translation is a well-defined mechanical activity. The belief of early workers has been described as follows :

That high quality translations could be produced by machines supplied with sufficiently detailed syntactic rules, a large dictionary, and sufficient speed to examine the context of ambiguous words for a few words in each direction (Lindsay, 1963). 
But the illusion did not endure. One of the prominent workers in machine translation of the 1950's and a dissenting voice in the 1960's was Bar-Hillel.

Bar-Hillel coined an acronym which is still used : FAHQT (Fully Automatic High Quality Translation). Bar-Hillel claimed that FAHQT was impossible. (Bar-Hillel, 1960) He claimed that a machine would never be programmed to produce quality translations unless the machine had a model of the real world as part of its program.

For example, consider Bar-Hillel's sentence "The box was in the pen." The word "pen" would certainly have several translations into most languages. In particular, the sense "animal enclosure" would translate differently from the sense "writing instrument".

Bar-Hillel argued that a machine-translation system would have to know something about the real world and in some way "understand" language to translate such sentences correctly. This conclusion should not be very startling to a translator. Semantics and pragmatics are well-recognized areas of linguistics, and every translator knows the importance of understanding the text being translated.

So Bar-Hillel's conclusion itself is not very interesting. It is interesting, however, to examine the reactions to his conclusion. Some discounted the importance of his observations. They claimed that if one specifies the subject matter of the text, the proper translation can usually be decided without regard to context and the few remaining errors are insignificant.

Others accepted Bar-Hillel's conclusion and took an all or nothing approach. They decided if FAHQT was impossible then machine-translation was of absolutely no interest.

These two reactions look at the same data in different ways. Take, for example, an ordinary typewriter. It will have keys for the alphabet, the digits, and a few punctuation marks. Now suppose the typewriter has parentheses but no square brackets. One attitude would discount the importance of the problem and use parentheses instead of brackets or write in the brackets by hand. The opposing attitude would claim the typewriter is useless and that hand printing is better since one can use any special symbol that can be drawn. Who is right?

This brings us to about 1966, when the National Science Foundation requested a report on the status of machine translation. This booklet, called the ALPAC report (ALPAC, 1966) was printed with an appropriate black cover. It immediately became the funeral announcement for significant funding of machine translation in the United States. The report was concerned mainly with the translation of Russian scientific articles into English by government agencies. The report claimed that there was at that time no shortage of human translators to do the work and that experiments in machine translation to that date had not produced fully automatic high quality translation. The conclusion of the report was as follows :

The committee believes that it is wise to press forward undaunted, in the name of science, but that the motive for doing so cannot sensibly be any 
foreseeable improvement in practical translation. Perhaps our attitude might be different if there were some pressing need for machine translation, but we find none (ALPAC : p. 24).

The report recommended that several centers be funded to investigate the basic problems of machine translation, but the attitude taken by most people was that since machine-translation had not been totally successful to date, machine translation was a total failure and of no interest to anyone. The ALPAC recommendation to continue basic research was generally ignored.

Since 1966, machine translation has been a "dirty word" in many circles and funding has been scarce.

Since the ALPAC report, there have been three new approaches to machine translation that have developed. None of them ignores the problems of machine translation and none is inclined to abandon the effort because FAHQT has not yet been achieved.

The first new approach is the Artificial Intelligence approach. Several workers in Artificial Intelligence have re-examined Bar-Hillel's argument that the resolution of certain ambiguities would require knowledge of properties of the real world. Bar-Hillel considered that the argument was closed because real-world knowledge in a computer was obviously impossible. Artificial Intelligence workers took that assumption as a challenge and began working on representing real world knowledge in computers. To date they have produced some very interesting results when restricted to micro-worlds which do not have very much knowledge that needs representation.

The second new approach to machine-translation is to restrict the subject matter to a well-defined sub-language and to design a system specifically for that sub-language. This is the approach of the TAUM project at the University of Montreal. The METEO system, mentioned at the beginning of this article, is currently being used daily by the Canadian Government to translate weather forecasts from English to French. The following example from the output of the METEO system shows that it produces more than a word-for-word translation :

Wind warning ended both regions

Fin de l'avis de vent pour les deux régions (Chandioux, 1976).

Both the Artificial Intelligence approach and the sub-language approach currently require highly restricted source text in order to obtain high quality translations. But suppose that translation of rather general text is needed. Then neither the Artificial Intelligence approach nor the sub-language approach is currently useful. A "first-generation" system such as those in the 1950's can handle a large vocabulary, but the translation produced for general text is considered to be too poor to be worth human post-editing. The third approach is to request human intervention during the actual translation process. The computer interacts with a human by means of a video display and a keyboard.

This interactive approach promises to produce translations of rather general text which are good enough to be worth post-editing. The Brigham 
Young University ITS project is an example of this approach (Melby, 1978). The success of the interactive approach depends on how well the computer can select which questions to ask and how much good having the answers does in improving the translation. At one extreme, an interactive system could ask for the translation of every phrase. Then, of course, there is no savings. If, on the other hand, it asks a few pertinent questions which require the human's knowledge of the real world to answer, there may be a considerable savings.

\section{AN INTERACTIVE TRANSLATION SYSTEM (ITS)}

The first version of the Brigham Young University Interactive Translation System was completed in 1980 after more than five years of development. ITS Version 1 had a substantial vocabulary (about 30000 word roots plus numerous fixed phrases) and was successfully used to translate several documents into Spanish, Portuguese, German, and French. However, the amount of humanmachine interaction required to produce the translations was rather high and ITS Version 1 is not being used for production translation. (See Appendix I for description of ITS Version 1) However, the experience gained has been very valuable and plans are now being made for Version 2. In addition, some of the members of the project have moved off campus and are developing machine aides to translation in a commercial environment.

\section{A LOOK AT THE FUTURE OF ITS}

The next version of ITS on the campus of Brigham Young University (BYU) will be developed under the BYU Language Research Center and will differ from Version 1 in several ways. First, it will be a one-to-one system rather than a one-to-many system. The idea of one-to-many translation tested in Version 1 was intriguing in that the overhead of interactive analysis was shared over several target languages. But that sharing also required a very complex analysis designed to please any target language. This is somewhat like trying to define a foreign policy which every citizen will approve of.

Work on the next version of ITS will concentrate on the problem of limiting interaction and making the questions more easily understood by the human operator without extensive training. Attention will also be given to the problem of making it easier for the operator to correct and extend the linguistic processing capabilities of the system.

The long range goal of this work at the BYU Language Research Center is to contribute in some way to the development of a useful translation work station.

The author forsees a translator's work station which would support two modes of operation. In one mode it would be a sophisticated but easy-to-use word processor. Of course, multiple character sets would be available on the video display and the typewriter-quality hardcopy device. The station would also 
contain a glossary which could be updated by the translator. Martin Kay (Xerox) is currently working on such a station, with his own variations.

In the second mode, the work station would be an interactive translation system. Source text could be entered directly from the keyboard, or the translator could insert a diskette containing the source text as it was first entered on a word processor for publication in the source language. At any rate, after the source text is entered, the station would interactively resolve ambiguities and other problems in the translation. The interaction, to be attractive, would have to average under ten minutes per page for a one-to-one translation and the output would have to be of such high quality that it could pass as a human translation with only a few minor post-edit changes per page. The work station would also have to be reasonably priced (less than a compact automobile).

Finally, and most importantly, the work station must work! That is, the station must be easy enough to use that the translator will want to use it. The first mode (word processor with dictionary lookup) must allow the translator to produce a quality translation faster and more conveniently than by manual methods. And the second mode (interactive translation system) must allow the translator to produce a quality translation faster than by using just a word processor.

When a work station such as the one just described comes about, there still may be few manual translators who will want to try it, even if it works. Of course, if it does work, translators will have to have been involved in its development. But once a few translators venture voluntarily to use it and find it makes them more productive and cost-effective, then the pressure to use it will come from within the translator community, not from outside.

This is one view of how the computer will be used in translation. Rather than replacing human translators, computers will serve human translators. It agrees with Andreyewsky's advice to translators : 'Instead of fighting a 'win/lose' battle with the machines, we must work toward developing an 'everybody win' frame of reference" (Andreyewsky, 1980).

\section{SUGGESTIONS TO TRANSLATORS}

In the author's opinion, this is an exciting time for translators. Various kinds of machine-aids will be used more and more. They will eventually raise the status of the translator's profession. One way for translators to prepare is to get acquainted with computers. This is much easier now than it used to be. A piece of word processing equipment is a little computer, and word processing equipment is becoming more and more sophisticated while it is becoming less expensive. Every translator should be able to find an office using word processing and try out the equipment. The author believes that word processing will be useful to a large number of translators before ITS will be.

Another way to prepare is to get involved in a machine translation project. This is not to say that every translator should be doing research. But every translation project needs one or more translators. 
Perhaps, one of the most important results of work on machine aids to translation will be an increased respect for the complexity and difficulty of creative human translation.

It is unclear how soon machine aids will be used by a significant number of translators, but movement in that direction is certain. Translators and machines can and will cooperate.

\section{REFERENCES}

ALPAC, Machines and Translation, Washington (D.C.), NAS/NRC, 1966.

ANDREYEWSKY, Alexander, "Whither Automation and the Translator"? ATA Chronicle, April/May 1980.

BAR-HILLEL, Yehoshua, "The Present Status of Automatic Translation of Languages", in Advances in Computers, vol. 1, New York, Academic Press, 1960.

CHANDIOUX, John, "METEO", TAUM Project, University of Montreal, 1976.

LINDSAY, R. K., "Inferential Memory as the Basis of Machines Which Understand Natural Language", in Computers and Thought, New York, McGraw-Hill, 1963.

MELBY, Alan K., "Interactive Translation", COLING 78, Bergen, Norway, 1978.

MILLER, G. A., "Language, Learning and Models of the Mind", unpublished manuscript, 1972.

SIMON, H. A. and A. NEWELL, "Heuristic Problem Solving", Operations Research, Vol. 6 (Jan.-Feb. 1958).

\section{APPENDIX}

\section{INTERACTIVE TRANSLATION SYSTEM DEMONSTRATION}

Translation Sciences Institute

Brigham Young University

Provo, Utah 84602

\section{Text Preparation}

Before a text can be processed by the computer, it must be in a form that the computer can read: punched cards, magnetic tape, etc. It is a necessary step in the processing, but it is essentially a straightforward clerical task, so it will not be discussed here.

\section{Interactive Analysis}

In the analysis step, the text is analyzed, sentence by sentence, and a meaning representation is produced for each sentence. This meaning representation contains all the information explicitly present in the sentence, plus contextual information which must be calculated from the explicit information, either in the particular sentence being processed or elsewhere in the text. The computer can handle most of the explicit information by itself, but contextual information is at present most efficiently provided by a human. So, the human operator and the computer work together in this step, the computer asking questions of the human by means of a video display terminal when something is not clear. To show how this happens, some example sentences will be presented, which illustrate some of the problems which must be handled in an interactive system.

The first thing the computer does to a sentence to be analyzed is to divide it into words and to look up each word in its dictionary. From the dictionary comes information 
about how each word can function in a sentence. Many words are unambiguous in this respect, that is, they can only function in one way, perhaps as a pronoun, or an adjective, or a verb. But many words are ambiguous as to their function. There are two or more ways they could be functioning in a sentence (for example, run could function as a verb or a noun). For words like this the computer examines the context of the lexical string for clues. Often, the context of the surrounding words will enable the computer to make the correct choice. However, when it cannot make the decision on its own, it displays appropriate questions on the screen for the human operator to answer.

\section{SCREEN 1}

ENGLISH ANALYSIS - STRUCTURAL DISAMBIGUATION

SENTENCE ID : 1 She $<1>$ called $<2>$ up $<3>$ the $<4>$ stairs $<5>$ to $<6>$ her $<7>$ sister $<8>$ after $<9>$ calling $<10>$ up $<11>$ her $<12>$ friend $<13>$ on $<14>$ the $<15>$ phone $<16>$. $<17>$

CATEGORY CLUSTER FOR : up $<3>$

1V Verb - They will have to up the price of gas.

2A Particle - You should look up the word in the book.

3P Preposition - They live just up the street.

SELECT CATEGORY

3 (confirm guess)

CONFLVL : 2

In this interaction, three possible functions for the word up $<3>$ are presented to the human operator. The computer has already examined the environment in order to provide its best guess as to the function of the word, which it displays in the lower left-hand corner, along with a confidence level, which gives the operator an idea of how reliable this guess is. (The higher the confidence level, the higher the probability that the guess is correct.) From looking at the context (a preceding verb and a following noun phrase), the computer guesses that $u p<3\rangle$ is functioning as a preposition. In this case that is correct, but notice that $u p$ also occurs as word number 11 in this sentence, in the same environment, but it is functioning as a particle in this instance, something which the computer cannot detect by itself.

\section{SCREEN 2}

\section{ENGLISH ANALYSIS - STRUCTURAL DISAMBIGUATION}

SENTENCE ID : $2 \mathrm{His}<1>$ voice $<2>$ is $<3>$ relaxing $<4>.<5>$

\section{CATEGORY CLUSTER FOR : is $<3>$}

$1 \mathrm{Vc}$ Copula - He is ill. It is kicked by me.

2Vp Progressive marker - He is swimming.

3 Ve Existential - There is a God in heaven.

SELECT CATEGORY

2 (enter 1)

CONFLVL : 2 
Sometimes a word which belongs to only one category can be associated with several structures. 'Is' is an example of this. The structure which needs to be built will be different depending upon whether it is functioning as a copula, a progressive marker, or an existential verb. By looking at the context, the computer guesses that this is is the progressive marker, because the word following ends with -ing. However, in this case, the participle relaxing does not refer to something his voice is "doing" (which the progressive reading would imply), but rather, relaxing refers to a "quality" his voice has. Consequently, it is functioning as a simple adjective, so the copula function of is would be the one to choose. The human operator can correct the compurer by simply entering the correct response.

\section{SCREEN 3}

\section{ENGLISH ANALYSIS - STRUCTURE BUILDING}

SEINTENCE ID : $3 \mathrm{We}<1>$ should $<2>$ avoid $<3>$ falling $<4>$ victims $<5>$ to $<6>$ error $<7>.<8>$

WHAAT IS falling $<5>$ ?

PROMPT: $\quad(N O U N|J=A D J| V=A D V) \quad P V \mid V$

GUESS : N PV

REPLY : (confirm guess)

Once dictionary information has been retrieved for each word, the next step is to build the meaning representation. Human interaction is needed here as well, because the proper relationships among words are not always obvious from the word order. For example, words with the -ing suffix can function in a variety of ways. They can be nominal, verbal, adjectival, or adverbial, and can consist of a single verb or a whole predicate. In this sentence, the human must determine whether it is the act of falling or the victims themselves that should be avoided. If falling were functioning as an adjectival participle, "avoiding falling victims" would be like avoiding falling rocks. This is not what is intended. Rather, it is the whole notion of "falling victims to error" which is to be avoided, which means that -ing is marking the nominalization of a predicate.

SCREEN 4

ENGLISH ANALYSIS - STRUCTURE BUILDING

SENTENCE ID : 4 The $<1>$ witch $<2>$ made $<3>$ the $<4>$ prince $<5>$ a $<6>$ frog $<7>.<8>$

WHAT IS frog $<7>$ ?

PROMPT: DO/NVP/APPOS

GUESS : DO

REPLY : (confirm guess)

When two or more nouns occur in sequence, it is difficult for the computer to determine how they are functioning in relation to each other. There are two interpretations of the above sentence. Once is that the witch made the prince into a frog. The second is that the witch made a frog for the prince. In the first case, prince is the 
direct object, and in the second case, frog is the direct object. So the program must interact to determine which structure is correct in the given context. Other interesting noun configurations which must be recognized by the program are: appositives (my friend John), noun/noun compounds (a two car garage), quantifiers (he drove his car 1000 miles), nouns functioning as adverbs (she gave the boy a book this morning), and others.

\section{SCREEN 5}

\section{ENGLISH ANALYSIS - REFERENTIAL DISAMBIGUATION}

SENTENCE ID : 5 I $<1>$ found $<2>$ the $<3>$ pen $<4>$ in $<5>$ the $<6>$ yard $<7>,<8>$

WHAT IS THE MEANING OF 'pen $<4>$, ?

GUESS : 1

REPLY : (confirm guess)

1. writing instrument

2. enclosure (e.g. children's play pen)

3. penitentiary

Once the structure has been built, contextual information is added to it. Many words are ambiguous, and in a variety of ways. They can be ambiguous as to word sense, as in the above example. Only context can determine which "pen" was found in the yard, and so the human operator is called upon to make the choice.

SCREEN 6

\section{ENGLISH ANALYSIS - REFERENTIAL DISAMBIGUATION}

SENTENCE ID : 6 The $<1>$ saboteur $<2>$ blew $<3>$ up $<4>$ the $<5>$ balloon $<7>.<8>$

WHAT IS THE MEANING OF 'blew $<3>$ up $<4>$ '?

GUESS : 1

REPLY : (confirm guess)

1. explode

2. inflate

3. enlarge

4. blow upwards

This semantic disambiguation occurs on groups of words as well, if they are to be considered as units. In the above sentence, 'blow up' is being considered as a unit (called a multi-word expression). Some expressions of this type are not ambiguous (for example, the expression 'to be fed up with' is not ambiguous, so it can be automatically recognized and passed on as a unit). However, many multiword expressions have several interpretations, so interaction is necessary to distinguish them. 


\section{SCREEN 7}

ENGLISH ANALYSIS - REFERENTIAL DISAMBIGUATION
$\begin{aligned} & \text { SENTENCE ID : } 7 \text { You }<1>\text { should }<2>\text { seek }<3>\text { divine }<4>\text { help }<5>\text { through }<6> \\ & \text { prayer }<7>,<8>\end{aligned}$
WHAT IS THE NUMBER OF 'you $<1>$ '?
PROMPT:
GUESS:
PLULULALAR :
(confirm guess)

Words can also be ambiguous as to number. The above admonition could be addressed to one person in particular, or to a whole audience of people. Only context tells. And whether you is singular or plural makes a great deal of difference in a translation.

\section{SCREEN 8}

ENGLISH ANALYSIS - REFERENTIAL DISAMBIGUATION

SEINTENCE ID : 8 The $\langle 1\rangle$ president $\langle 2\rangle$ is $\langle 3\rangle$ arriving $\langle 4\rangle$ at $\langle 5\rangle$ the $\langle 6\rangle$ airport $\langle 7\rangle$ $.<8>$

WHAT IS THE RELATIVE TENSE OF ' is $<3>$ '?

PROMPT : CONTEMPORANEOUS/POSTERIOR

GUESS : CONTEMPORANEOUS

REPLY : POSTERIOR

Another possible ambiguity is tense on verbs. The above sentence could be a statement of what is happening right this minute, or it could be a statement of a future event. Lexically, the verb is present progressive, but context provides the actual time frame.

\section{Precision Interactions}

Once the analysis process described above has been completed, a meaning representation is saved for each sentence. Then a few precision questions may be asked for each target language to resolve word choice questions that cannot be made automatically from the information produced by English analysis.

\section{Automatic Transfer and Synthesis}

Once the interactions are completed, the machine can produce translations of the text in multiple target languages. This step is automatic - it requires no human interaction, so it can be run on the computer at night or during other off hours.

\section{First Review}

The automatic translation step saves the translated text so that it may be reviewed and edited. The first review examines the text sentence by sentence to take 
care of problems that the computer system cannot currently handle. The reviewer is provided with the original sentence as it was entered in English, the machine translated sentence in the target language, and other miscellanious information to identify the sentence and to provide formating instructions. The operator can then compare the English and the target sentence and make any corrections necessary. The terminal capabilities for deletion or insertion of text and for other changes make this type of editing much faster and easier than the traditional approach of marking the text and retyping it.

\section{Second Review}

Following the first review, the text sentences are processed and formatted in paragraph form. In this new format, the second review takes place. This format allows the reviewer to consider each sentence in the context of the whole text. When this review is completed, the text may be type-set automatically and sent to press. 